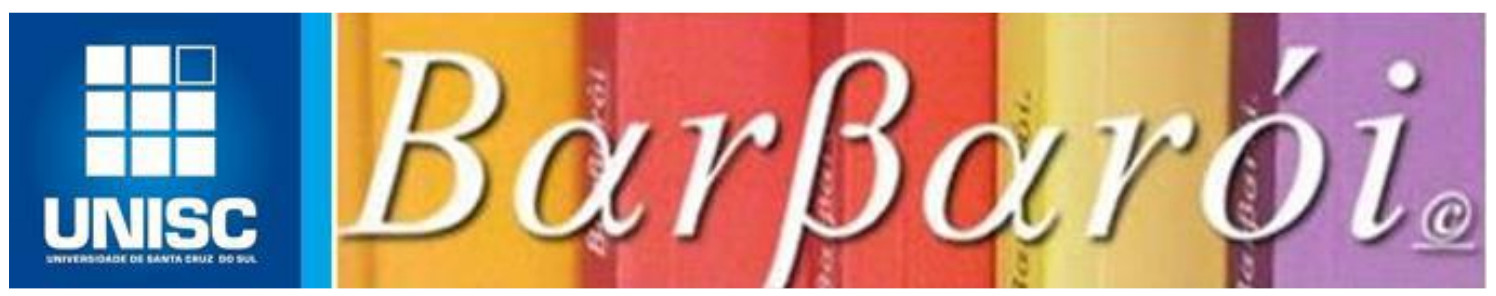

\title{
BOLSA FAMÍLIA: POTENCIALIDADES E DESAFIOS NA INDUÇÃO DE POLÍTICAS PÚBLICAS A PARTIR DOS TERRITÓRIOS
}

DOI: http://dx.doi.org/10.17058/barbaroi.v0i0.13971

\author{
Eduardo Guadagnin \\ Universidade do Vale do Rio dos Sinos - UNISINOS - Brasil \\ Pedro Ribeiro Moreira Neto \\ Universidade do Vale do Rio dos Sinos - UNISINOS - Brasil \\ Paula Vilhena Carnevale Vianna \\ Universidade do Vale do Rio dos Sinos - UNISINOS - Brasil

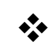

\section{Resumo}

O presente artigo analisa as potencialidades e limites do programa Bolsa Família em direcionar as políticas sociais nos territórios, favorecendo o acesso aos direitos sociais básicos e a redução da exclusão social das famílias acompanhadas. A análise da bibliografia apoiou-se nos conceitos de lugar e território propostos por Milton Santos, bem como nas concepções de representações sociais e comunidade, tendo, como referencial teórico, a perspectiva territorial das políticas sociais. A revisão bibliográfica, combinada à reflexão acerca da prática cotidiana do acompanhamento das condicionalidades do programa em uma unidade de saúde da família de um município de médio porte paulista, evidenciou que o acompanhamento das condicionalidades do Programa Bolsa Família pode favorecer tanto o acesso das famílias com maior vulnerabilidade social aos serviços saúde, educação e assistência social quanto a ampliação dos direitos sociais e redução da exclusão social. Porém, para que isso se efetive, é necessário que gestores e profissionais que operam as políticas sociais nos territórios compreendam as condicionalidades a partir de um olhar emancipatório e de garantia de direitos, rompendo com a postura fiscalizatória/punitiva fundamentada na concepção assistencialista e meritocrática. Também é necessária a garantia de acesso a serviços de qualidade no território, organizados para assegurar os direitos sociais básicos dos cidadãos. A intersetorialidade permite um olhar ampliado sobre os territórios usados, favorecendo a compreensão da comunidade em que os usuários e famílias estão inseridos.

Palavras-chave: Território, políticas sociais, Programa Bolsa Família. 


\section{Introdução}

O presente artigo toma o território como elemento central para análise das políticas sociais de base territorial. Enfoca o Programa Bolsa Família, considerando-o como elemento de agregação das ações junto a famílias em situação de vulnerabilidade social, na perspectiva de ampliação do acesso aos serviços e redução dos fatores geradores da desigualdade e exclusão social. Apoia-se nos conceitos de território usado e lugar do geógrafo Milton Santos (2005, 2006), sendo o território usado o espaço humano, o espaço habitado; que dialoga diretamente com o conceito de lugar, compreendido como um intermédio entre o mundo e o indivíduo.

A concepção de cidadania é aqui fundamentada pela construção de um território comum, que abriga uma comunidade política em que os indivíduos são incluídos e compartilham de um mesmo sistema de crenças e de um conjunto de direitos e deveres. Esta tem como base a cultura cívica e pressupõe um modelo de integração e sociabilidade pautado em valores como liberdade, igualdade e solidariedade, como ressaltam Fleury e Ouverney (2014), em análise conceitual sobre as políticas sociais.

O modo de produção capitalista necessita, em princípio, da igualdade e liberdade dos indivíduos para o estabelecimento de relações de trocas, protegidas por um poder político (o Estado) que atua em nome de todos e é legitimado pelos cidadãos. Porém, simultaneamente, porta em si, como elementos constituintes, a desigualdade econômica e a exploração da mão de obra para a obtenção de lucro. Essa contradição essencial do capitalismo exige a atuação do Estado para o equilíbrio social, o que se dá por meio da construção e implantação de políticas públicas (id, ibid).

Nesse contexto, a pobreza e a precariedade das condições de vida emergem como uma questão social a ser enfrentada coletivamente pelo Estado, por meio de políticas de proteção social que buscam minimizar os conflitos entre capital e trabalho, evitar a ruptura da coesão e possibilitar a reprodução da força de trabalho, pelas políticas de proteção, construídas como formas de prover a estabilidade e segurança anteriormente ofertadas por organizações tradicionais, como a família.

A implantação do sistema de proteção social no Brasil, na lógica da seguridade social, ou seja, universal como direito, garantida pelo Estado, se deu a partir da Constituição Federal 1988, sendo fruto de um amplo processo de mobilização da sociedade. A crise econômica do final da década de setenta e início da década de oitenta, somada à precariedade das condições de vida nos grandes centros urbanos e o desejo expresso pela sociedade de por fim ao governo 
autoritário e estabelecer um estado democrático de direitos favoreceram a mobilização de inúmeros grupos em todo o país que reivindica a garantia de direitos universais como saúde, educação, habitação, segurança e transportes.

A constituição de 1988, considerada como a constituição cidadã, é um marco na garantia de direitos universais no país. Já em seu preâmbulo afirma a intenção da implantação de um "Estado Democrático, destinado a assegurar o exercício dos direitos sociais e individuais, a liberdade, a segurança, o bem-estar, o desenvolvimento, a igualdade e a justiça como valores supremos de uma sociedade" (BRASIL, 1988, preâmbulo).

Estabelece, nesse sentido, que "a seguridade social compreende um conjunto integrado de ações de iniciativa dos Poderes Públicos e da sociedade, destinadas a assegurar os direitos relativos à saúde, à previdência e à assistência social” (BRASIL, 1988, art.194).

Fleury (2012, p. 1) aponta o caráter abrangente da seguridade social adotada pela Constituição de 1988 e a orientação para a organização de "programas e políticas direcionados para a promoção e inclusão dos grupos mais vulneráveis”. Reforça, também, a importância do caráter territorial de tais políticas, que devem ser adotadas considerando as particularidades dos espaços de vida dos cidadãos. No entanto, apesar de a Constituição estabelecer a garantia legal de um sistema de proteção social, o Brasil, entre 1970 e 2000, foi considerado o país mais injusto do mundo, segundo qualquer medida de avaliação da desigualdade (CARIELLO, 2013). Não se trata de afirmar que o Brasil é um país pobre, pois está entre os $25 \%$ dos países com maior renda per capita do mundo, porém a distribuição se dá de forma extremamente desigual.

Amaral e Monteiro (2013) afirmam que a redução das desigualdades deve ser priorizada para o alcance de melhoria nas condições de vida das populações mais pobres. Nesse sentido, segundo o IPEA - Instituto de Pesquisa Econômica Aplicada, o cenário da desigualdade se alterou a partir do início do século XXI. Na análise de série histórica entre os anos 1999 e 2011, observa-se tendência de redução da desigualdade na distribuição de renda, sendo que a queda foi mais acentuada entre 2001 e 2005 e permaneceu em declínio durante todo o período (IPEA, 2007). Ainda segundo os pesquisadores do IPEA (2007, p.5) a redução da desigualdade no país, neste período, está fortemente vinculada com a "evolução da renda não derivada do trabalho", mais especificamente, ao programa de transferência de renda do governo federal - Bolsa Família. 
A análise da série histórica de 2004 a 2014 demonstra uma redução constante da desigualdade social, sendo o Programa Bolsa Família um dos fatores responsáveis por esta redução (IPEA, 2015).

Arretche (2017) ressalta que a Constituição Federal de 1988 trouxe medidas que favoreceram a inclusão dos outsiders (excluídos), através a vinculação de aposentadorias não contributivas ao salário mínimo, políticas de transferência de renda e a universalização dos sistemas de saúde e educação. Medidas essas que interferem na redução da desigualdade monetária e não monetária, a primeira vinculada ao aumento da renda e a segunda ao acesso a serviços básicos. Neste sentido, os estudos do IPEA apontam que o Programa Bolsa Família tem impactado na situação de desigualdade no país, porém há de se questionar: considerandose as condicionalidades do programa e o atendimento pretendido às necessidades sociais, o Programa Bolsa Família tem direcionado as políticas públicas nos territórios, de modo a favorecer a efetivação dos direitos das famílias em situação de extrema pobreza e o acesso aos serviços sociais, reduzindo assim a vulnerabilidade socioterritorial.

Este estudo tem como objetivo geral analisar se o acompanhamento das condicionalidades do Programa Bolsa Família em uma unidade de saúde da família de um município paulista de médio porte tem favorecido, ou não, o acesso dos usuários aos serviços de saúde, educação e assistência social. Dirige um olhar especial à ação dos serviços e profissionais sobre os fatores geradores da exclusão socioespacial.. A pesquisa é qualitativa, exploratória, do tipo estudo de caso. Parte de uma pesquisa empírica baseada na prática de um dos autores em uma unidade de saúde da família na periferia de um município paulista de médio porte, aqui significado para efeito deste trabalho como uma unidade de pouco mais de 200 mil habitantes e inserido em funções intermediárias ne sistema regional. As anotações de campo, registradas em diário, incluíram participação em reuniões intersetoriais, atendimentos clínicos, visitas domiciliares e atividades socioeducativas no território da unidade de saúde da família. Os registros de campo foram analisados a partir da questão de pesquisa, buscando-se tanto o diálogo com a revisão bibliográfica sobre o tema como a busca de novas perspectivas de análise.

$\mathrm{O}$ artigo se divide em três partes, inicialmente a conceituação do Programa Bolsa Família e as representações às quais este se alude para, em seguida, analisar seus resultados na prática profissional em uma unidade de saúde, experiência à qual se apoiam as reflexões finais. 


\section{O Programa Bolsa Família: conceitos e representações}

O Programa Bolsa Família surge como proposta alternativa para a redução das disparidades na distribuição de renda no país e sob aspectos técnicos visa à transferência de renda para famílias em situação de extrema pobreza. Para tanto, estabelece um conjunto de condicionalidades justificadas pela necessidade de promover o acesso aos direitos sociais básicos e de romper o ciclo intergeracional da pobreza (BRASIL, 2004).

Baseia-se em uma concepção de pobreza multideterminada, que vai além da falta de renda que deve ser superada; visa o fortalecimento das capacidades dos indivíduos e sua inclusão social. Nessa perspectiva, o efetivo combate à pobreza requer um programa abrangente, que impacte nas vulnerabilidades a ela associadas (SANTOS, 2011).

Ximenes e Agatte (2011, p. 12) ao analisarem o Programa Bolsa Família, apontam que sua execução se relaciona não apenas ao alívio imediato da pobreza, pela transferência direta de renda, mas, igualmente, à ruptura do ciclo geracional da pobreza, por meio do acesso a serviços de saúde, educação e assistência social e à disponibilidade de programas complementares para o apoio do desenvolvimento familiar.

Para tanto, o Programa Bolsa Família vincula a transferência de renda ao cumprimento de condicionalidades por parte das famílias nas áreas de educação, saúde e assistência social. As condicionalidades previstas são:

a matrícula e frequência escolar mínima de $85 \%$ para crianças e adolescentes entre 6
e 15 anos e de $75 \%$ para jovens de 16 e 17 anos; o acompanhamento do calendário
vacinal e do crescimento e desenvolvimento para crianças até 7 anos, do pré-natal
para gestantes e puerpério (XIMENES; AGATTE, 2011, p. 12).

Segundo os mesmos autores as condicionalidades têm como objetivo "reforçar o acesso das famílias beneficiárias às políticas de educação, saúde e assistência social, promovendo a melhoria das condições de vida, bem como levar o poder público a assegurar a oferta desses serviços" (id, ibid.). Configuram-se, dessa maneira, como um compromisso de mão dupla entre as famílias beneficiárias e o poder público, visando à ampliação do acesso das famílias aos serviços sociais, o que potencialmente romperia o processo de transmissão intergeracional da pobreza. $\mathrm{O}$ acompanhamento das condicionalidades aumentaria a chance de efetivação dos direitos sociais daqueles que, historicamente, têm sido excluídos das políticas sociais. Nesse sentido o acompanhamento das condicionalidades favoreceria o acesso aos serviços de sociais básicos, reduzindo a desigualdade não monetária (ARRETCHE, 2017).

Portanto os conceitos específicos e fundamentais para caracterização do Programa Bolsa Família são: pobreza, exclusão e política social territorializada. 


\section{Conceitos fundamentais do Programa Bolsa Família}

Para que o PBF tenha um caráter emancipatório, que fortaleça a cidadania e rompa com os padrões de pobreza e exclusão social, deve ser orientado pela perspectiva da seguridade social, ou seja, da garantia de condições mínimas de vida digna a todos os cidadãos. Essa construção não se dá em um espaço abstrato, mas a partir de territórios concretos.

Em uma simplificação, com finalidade de contextualizar o processo de formulação de uma política social na contemporaneidade, podemos considerar que há dois projetos societários em disputa no país e no mundo. Um, de viés progressista, aposta na redução das desigualdades sociais e na ampliação de direitos universais dos cidadãos; o outro, de caráter conservador, neoliberal, aposta em uma visão individualista em que cada um deve ser responsável pela satisfação de suas necessidades individuais e familiares. No primeiro, o Estado desempenha papel fundamental, coordenando, orientando e implantando políticas públicas sociais; no segundo, seu papel é menor, caracterizado como Estado mínimo, teria como função a manutenção da reprodução do trabalho, o apaziguamento das tensões sociais e a manutenção da coesão social (FLEURY, 2004; FLEURY, OUVERNEY, 2014).

Nesse cenário, a depender da orientação que nortear sua efetivação, o PBF poderá ser tanto estratégia para redução das desigualdades sociais e da pobreza, como um instrumento de manutenção do status quo, reduzindo a pressão sobre o modo de produção capitalista.

Conforme aponta Koga (2013, p. 31), as necessidades das políticas sociais brasileiras romperem com o "paradigma societário pautado sob a égide da pobreza como caricatura e, por isso, passível de ser personificada e identificada a partir de determinadas características individuais, que configurariam a pessoa do pobre". Nesse sentido, a pobreza é naturalizada como um componente da paisagem urbana, aceita pelos cidadãos, não gera estranhamento em suas diversas formas de expressão (KOGA, 2013). Koga (2013) nos convida a romper com essa representação do pobre e da pobreza, avançando as políticas sociais para além da caracterização das pessoas e famílias a serem atendidas de modo focalizado e imergindo em seus territórios de vida, a fim de compreender as condições concretas de vida nos territórios, considerando o acesso aos direitos de cidadania, inclusive à urbanidade. A autora salienta que os avanços obtidos com a Política Nacional de Assistência Social ainda não foram suficientes para superar a perspectiva homogeneizadora que segmenta e desconecta as políticas e ações a elas vinculadas dos territórios concretos e singulares de vida. Superar essa visão homogeneizadora, que não contempla as dinâmicas específicas de vida e exclusão em cada 
território, é, para Koga (2013), um desafio para as políticas sociais. E esse desafio se insere no campo de disputa política referido anteriormente, entre o paradigma do direito e da proteção social e o paradigma neoliberal, que imputa à família a responsabilidade pelo provimento das necessidades individuais.

As necessidades individuais e coletivas, no modo de produção capitalista, podem ser analisadas à luz de dois fenômenos complementares, objetos de políticas sociais: a desigualdade e a exclusão social. A desigualdade pode ser compreendida como um fenômeno socioeconômico, enquanto a exclusão é um fenômeno cultural e social (SANTOS, 1995).

Superar a exclusão social requer a superação da visão binária, excluído-incluído, e introdução de uma compreensão deste fenômeno em sua natureza dinâmica e processual (FLEURY, 2004). Ou, como apontam Curralero e Afonso, a pobreza deve ser enfrentada para além da insuficiência de renda, compreendendo-se o aspecto de múltiplas privações e vulnerabilidades geradores de "círculos perversos de exclusão" e se constituem no grande desafio para a gestão do PBF e das políticas sociais, em especial. Isto porque se faz necessário romper com os fatores que retroalimentam a pobreza como a desigualdade, dinâmicas do mercado de trabalho e vulnerabilidades múltiplas (2011, p. 7),

A Política Nacional de Assistência Social considera essas dimensões e perspectivas, como se observa por aportar

\footnotetext{
uma visão social inovadora, pautada na dimensão ética de incluir "os invisíveis" enquanto integrantes de uma situação social coletiva; uma visão que exige o reconhecimento para além das demandas setoriais e segmentadas, afirmando que o chão onde se encontram e se movimentam setores e segmentos fazem a diferença no manejo da própria política; uma visão social que exige relacionar as pessoas e seus territórios, identificando no cotidiano do "território vivido", os riscos e vulnerabilidades, mas também as potencialidades e os recursos disponíveis; uma visão que se pauta na perspectiva socioterritorial, cujas intervenções se dão nas capilaridades dos territórios, a partir do reconhecimento da dinâmica que se processa no cotidiano das populações (BRASIL, 2005a, p. 15).
}

A compreensão das desigualdades sociais só é possível a partir dos territórios concretos, com suas dinâmicas, ocupações e relações, permeadas por representações sociais construídas no espaço intersubjetivo. Esse processo é entremeado pelas representações que os profissionais de saúde, educação e assistência social, que operam as políticas sociais nos territórios, têm sobre direitos e como eles se materializam na construção de cidadania.

\section{Representações sociais dos profissionais e a especificidade do PBF}

Para se analisar como as representações dos profissionais que operam as políticas sociais em sua prática cotidiana, na relação com os usuários, interferem no modo de 
organização do programa é necessário conceituar representações sociais e compreender como se constroem.

Sandra Jovchelovitch é uma das autoras em psicologia social que se dedica a estudar e compreender o tema das representações sociais. Segundo a autora representações são feitas de símbolos, em que os indivíduos utilizam de sua capacidade psíquica para dar às coisas uma nova forma, um novo significado. As representações sociais se articulam simultaneamente com a vida coletiva de uma comunidade e com os sujeitos sociais que buscam dar sentido ao mundo e encontrar seu lugar nele, por meio de uma identidade social. Nesse sentido, as representações sociais, como fenômenos psicossociais, ocorrem necessariamente nos espaços públicos (JOVCHELOVITCH, 1995).

A vida social se materializa no espaço público de forma direta, por exemplo no espaço das ruas, praças, em rituais coletivos, ou, indiretamente, por meio de instituições. Em ambos os modos, nos espaços e na convivência públicos, pela alteridade, se constituem representações sociais e, pela contraposição ao outro, se estabelece o desenvolvimento simbólico e a constituição do Eu. As representações sociais são efetivadas no espaço público, por meio de uma esfera pública, que permite a construção de preocupações e projetos comuns. Como coloca Jovchelovitch $(1995$, p.71) a esfera pública é “... o lugar em que uma comunidade pode desenvolver e sustentar saberes sobre si própria - ou seja, representações sociais".

A partir das reflexões sobre representações sociais de Jovchelovitch (1995) pode se supor que as representações que os profissionais constroem acerca dos usuários, da comunidade, do seu trabalho e de uma política social como o PBF, são elaboradas a partir das relações entre os próprios trabalhadores e destes com os usuários a quem atendem.

Dependendo das representações sociais dos gestores e das equipes de saúde, educação e assistência social que acompanham as condicionalidades do PBF, sobre direitos sociais e o papel do PBF na garantia destes direitos, o programa poderá, em sua implementação, adquirir diferentes feições. Poderá se configurar como política emancipatória ou manter o caráter fiscalizatório/punitivo, perpetuando a perspectiva assistencialista, em que se espera que as famílias mereçam, pelo cumprimento das condicionalidades, o benefício recebido do Estado.

Stechi (2015), em pesquisa qualitativa sobre as condicionalidades do PBF no município de Londrina, a partir de entrevistas semiestruturadas com gestores, profissionais e beneficiários do PBF, observou que os gestores do programa e os profissionais que o operam partem de uma crença que os pobres são incapazes por si só de tomar decisões racionais, 
devendo ser constrangidos através das condicionalidades a adequar seu comportamento ao esperado pela sociedade. A autora salienta:

a fala dos (as) técnicos (as) entrevistados (as) revelam que muitas vezes o olhar das políticas não é no sentido de proteção social, na perspectiva de garantia de direitos. $\mathrm{O}$ olhar está carregado de preconceito em relação à condição que aquele cidadão se encontra e de sua necessidade de amparo do Estado, entendendo-se como um favor. Distancia-se da responsabilidade que deve ser cobrada do Estado por implementar e garantir políticas de proteção social (STECHI, 2015, p.49).

Nessa perspectiva meritocrática, o cumprimento dos requisitos exigidos é priorizado, como valor, para o recebimento do benefício fornecido pelo Estado; em contraposição, o acompanhamento das condicionalidades numa perspectiva emancipatória permitiria às equipes a identificação das vulnerabilidades que dificultam o acesso das famílias aos serviços sociais básicos (XIMENES e AGATTE, 2011). Os autores apontam que o acompanhamento das condicionalidades do Programa Bolsa Família "permite uma abordagem integral tanto das famílias, em sua trajetória de vida, quanto das ações voltadas para o enfrentamento das situações de vulnerabilidade" (XIMENES; AGATTE, 2011, p. 12).

Silva e Alcântara (2012), na mesma perspectiva, salientam que o acompanhamento das condicionalidades visa à identificação das vulnerabilidades das famílias, sejam fatores que dificultam o acesso aos serviços sociais e/ou a inadequação dos mesmos em responder às necessidades dos usuários.

\section{Um outro modus operandi: organização territorial do processo de trabalho e fortalecimento das comunidades}

Processos de trabalho que não trazem o usuário como centro da prática profissional cotidiana dificultam o olhar aprofundado para as famílias acompanhadas pelo PBF e suas relações no "território usado" ou "lugar", como conceituados por Milton Santos. Para Santos (2005, p.255), o território usado é “o espaço humano, espaço habitado". O conceito de território usado dialoga diretamente com o conceito de lugar, uma vez que "os lugares, ..., podem ser vistos como um intermédio entre o Mundo e o Indivíduo" (SANTOS, 2006, pg. 212). Segundo o autor:

\footnotetext{
"no lugar - um cotidiano compartido entre as mais diversas pessoas, firmas e instituições - cooperação e conflito são a base da vida em comum. Porque cada qual exerce uma ação própria, a vida social se individualiza; e porque a contiguidade é criadora de comunhão, a política se territorializa, com o confronto entre organização e espontaneidade. O lugar é o quadro de uma referência pragmática ao mundo do qual the vêm solicitações e ordens precisas de ações condicionadas, mas é também o teatro insubstituível das paixões humanas, responsáveis, através da ação comunicativa, pelas mais diversas manifestações da espontaneidade e da criatividade (SANTOS, 2006, pg. 218)".
} 
O conceito de lugar de Milton Santos dialoga com o conceito de comunidade de Sandra Jovchelovitch. A autora aponta a importância da comunidade no processo de representação social, fazendo a interface entre o mundo particular da família e a regra geral da sociedade, permitindo ao indivíduo sentir-se parte do grupo e compreender o código de representações referentes ao mundo que os rodeia. A comunidade nos dá a possibilidade de compreender o outro a partir das representações sociais estabelecidas naquele grupo, proporcionando com isso relação empática com os outros à nossa volta (JOVCHELOVITCH, 2004).

Além de funcionar como referência para a constituição do sujeito, a comunidade possibilita o estabelecimento de relações e construção de espaços intersubjetivos que favorecem e asseguram a constituição da identidade do eu. Permite ainda, a produção de fenômenos como a comunicação, o diálogo entre identidades sociais, a memória social e a vida pública, articulando um conjunto de saberes sociais (JOVCHELOVITCH, 2004).

Jovchelovitch (2004) ressalta ainda a importância das comunidades para desenvolvimento e solução de problemas sociais e a situa como espaço mediador para o desenvolvimento da participação na esfera pública, favorecendo assim o desenvolvimento e a preservação das democracias. Nessa perspectiva, a comunidade se constitui como elemento fundamental para análises nos campos da saúde, política, educação e segurança pública (JOVCHELOVITCH, 2004).

A compreensão sobre as comunidades em que os usuários estão inseridos é fundamental para ruptura com a visão homogeneizante sobre pobreza, desigualdade social e exclusão social, por possibilitar a compreensão das vulnerabilidades das famílias acompanhadas pelo programa de forma concreta e ampliada.

A análise de como as vulnerabilidades - e, igualmente, os recursos disponíveis - se materializam nos territórios usados e nas diferentes comunidades permite a identificação de rugosidades, brechas para intervenção das equipes na realidade. A visão territorial possibilita a construção de um olhar para a realidade a partir da busca da garantia de direitos para os beneficiários do programa. Essa forma de olhar permite a construção de representações sociais elaboradas de forma compartilhada, nos espaços intersubjetivos, entre trabalhadores e usuários, que favorecem a ruptura dos mecanismos de manutenção da exclusão social (KOGA, 2013). 


\section{Análise e reflexões a partir da prática: o PBF em uma unidade de saúde da família na}

periferia de um município paulista de médio porte

A análise reflexiva realizada aponta potencialidades e desafios no acompanhamento das condicionalidades do PBF e na ampliação do acesso dos beneficiários aos serviços de saúde, educação e assistência social.

A experiência recente de um dos autores em uma Unidade de Saúde da Família, em uma região de alta vulnerabilidade social, de um município de médio porte do Vale do Paraíba Paulista dialoga com alguns dos desafios e potencialidades apontadas nos estudos pesquisados.

O território da unidade de saúde da família (UMSF) estudada contempla três bairros e uma área de ocupação, sendo a maior parte urbanizada, com asfaltamento das ruas, saneamento básico, coleta de lixo e comércio diversificado, com exceção da área de ocupação, que não possui infraestrutura básica.

A área adscrita da USF fica distante $10 \mathrm{~km}$ do centro da cidade e é fisicamente delimitada por barreiras antrópicas (a rodovia BR-116, Presidente Dutra) e naturais (Rio Paraíba do Sul e Rio Comprido). Essas características espaciais dificultam o acesso a outras regiões da cidade e favorecem, quando não impõem, uma maior interação entre os moradores do território.

Da população de 10.587 habitantes, 3.187 famílias são cadastradas pela USF, das quais $615(19,3 \%)$ são beneficiárias do Programa Bolsa Família - PBF. A faixa etária predominante é de adultos jovens, com uma porcentagem significativa de adolescentes (1.089, 10,3\% da população total). A grande quantidade de crianças e adolescentes no território demanda diversas ações dos equipamentos sociais (creches, escolas, UMSF, CRAS, projeto contraturno) buscando o atendimento das necessidades dos mesmos e o enfrentamento das situações de vulnerabilidade. Apesar de haver uma predominância de jovens na região a proporção de idosos também é relevante $(1.408 ; 13,3 \%)$ e impacta no perfil epidemiológico, que apresenta alta prevalência de doenças crônicas como hipertensão $(1.433 ; 13,5 \%)$ e diabetes $(542 ; 5,1 \%)$ e necessidade de atendimentos domiciliares (163 pacientes domiciliados e/ou acamados). Além da demanda de atendimentos em saúde, os idosos também demandam uma atenção especial do CRAS, devido às situações de vulnerabilidade social (PMJ, 2019). Entre as situações de vulnerabilidade desse território que impactam a saúde e qualidade de vida dos moradores, a equipe da USF identifica deficiências físicas do ambiente, como moradias precárias, associadas a várias famílias morando em um mesmo terreno; hábitos e 
atitudes prejudiciais como tráfico de drogas e uso abusivo de drogas; fatores estruturais econômicos, como desemprego, que se associam aos altos índices observados de gravidez na adolescência, violência doméstica e sexual, homicídios e suicídios. Essas situações de vulnerabilidade impactam nos indicadores socioeconômicos e epidemiológicos e demandam um acompanhamento próximo das equipes das políticas sociais.

Para o atendimento desta demanda o território contempla unidade de pronto atendimento - UPA, unidade de saúde da família - UMSF, centro de referência em assistência social - CRAS, duas creches, escola municipal de educação infantil - EMEI, escola municipal de ensino fundamental 1- EMEF, escola estadual de ensino fundamental 2, escola estadual de ensino fundamental 2 e médio, um Educamais (projeto integrado de educação, cultura, esporte e lazer), quadra poliesportiva coberta, projeto de assistência no contra turno escolar para crianças carentes, posto policial, igreja católica e evangélicas.

A mídia e o senso comum representam o território como violento, com forte presença do tráfico drogas, abrigando jovens sem perspectiva de vida, em que brigas são comuns e a coesão social é baixa. Tal representação encobre os movimentos passados e presentes de mobilização popular em busca por direitos e melhoria da qualidade de vida. Historicamente, a região vivenciou movimentos por habitação, asfaltamento, saúde e educação, que contribuíram para a instalação dos equipamentos sociais descritos acima. Essas conquistas são frequentemente relembradas pelos moradores que vivenciaram os movimentos. Atualmente existem iniciativas comunitárias por regularização da área de ocupação e projetos com crianças e adolescentes (escolinha de futebol e judô).

A UMSF possui quatro equipes de saúde da família, compostas por médico(a), enfermeira, técnicas/auxiliares de enfermagem e agentes comunitários(as) de saúde; além desta equipe nuclear, conta ainda com uma pediatra, duas dentistas, três auxiliares de consultório dental, um psicólogo, cinco recepcionistas, uma auxiliar administrativa e equipe de limpeza terceirizada. Há a necessidade de ampliação do número de agentes comunitários, para atender a ocupação na área de abrangência da unidade. $O$ déficit de pessoal não impede a equipe de tentar acompanhar todas as famílias do território, priorizando aquelas em situação de maior vulnerabilidade social e de saúde.

O acompanhamento das condicionalidades do PBF é feito no atendimento de rotina, sem um dia específico, como organizado na unidade de Manguinhos analisada por Magalhães et. al. (2011). Embora não se priorize o atendimento dos beneficiários do programa, os casos de maior vulnerabilidade são discutidos em reuniões semanais de equipe. Participam das 
reuniões semanais médico(a), enfermeira, técnicas e auxiliares de enfermagem, agentes comunitários(as) de saúde e dentista. A médica pediatra, o psicólogo e as auxiliares de consultório dental normalmente não participam das reuniões. As reuniões de equipe semanais contribuem para o cuidado integral às famílias em maior vulnerabilidade e o acompanhamento das famílias com maior dificuldade em cumprir as condicionalidades da saúde do PBF consensualmente reconhecidas pela equipe.

Nessas reuniões, as famílias com maior vulnerabilidade social e de saúde são discutidas. Os agentes apresentam a situação atual e são avaliadas as ações definidas anteriormente e estabelecidas as que serão desenvolvidas no próximo período. As ações incluem visitas domiciliares, atendimento domiciliar, agendamento de consulta médica, odontológica, psicológica e de enfermagem, encaminhamento para especialistas e a necessidade de articulação com outros serviços da saúde ou o desenvolvimento de ações intersetoriais.

Nos casos mais complexos são elaborados Projetos Terapêuticos Singulares - PTS (Brasil, 2007). O PTS é um dispositivo para organização do processo de trabalho que utiliza ferramentas do planejamento a partir de uma compreensão ampliada sobre o processo saúdedoença, no qual uma equipe discute problemas de saúde e avalia as vulnerabilidades e os recursos que podem ser mobilizados pela família, estabelecendo um plano compartilhado de cuidado. Em situações de maior vulnerabilidade social, após a elaboração do PTS pela equipe, são convidados para discussão conjunta outros atores do território, como o Núcleo de Apoio à Saúde da Família - NASF, o Centro de Referência em Assistência Social - CRAS, o Centro de Referência Especializado em Assistência Social - CREAS, a escola e o Conselho Tutelar. Essas reuniões conjuntas tem sido um momento importante para o estabelecimento de ações intersetoriais junto às famílias em situação de vulnerabilidade social e frente ao descumprimento das condicionalidades do PBF.

A unidade de saúde da família desenvolve ações de assistência individual e diversas ações coletivas com grupos de maior vulnerabilidade, incluindo os beneficiários do PBF como: grupos terapêuticos infantis, grupos terapêuticos com adultos, grupos de caráter socioeducativo com crianças e adolescentes, grupos de promoção da saúde (caminhada, ervas medicinais, alimentação saudável e viva leite) e ações de prevenção da saúde (suicídio, câncer de mama, de útero e de próstata, saúde bucal, vacinação, hipertensão e diabetes). Além das ações coletivas desenvolvidas na unidade de saúde, são desenvolvidas ações intersetoriais nas escolas, creches, igrejas, CRAS e no Educamais. 
Um dos pontos abordados na revisão bibliográfica se relaciona ao acesso e à qualidade dos serviços de saúde, educação e assistência social existentes no território em que vivem os beneficiários do PBF. Não é possível cobrar das famílias o cumprimento das condicionalidades se os serviços disponíveis forem de difícil acesso e baixa qualidade.

Santos e Lício (2011), em seu estudo sobre o acompanhamento nacional do PBF, apontam como um dos desafios para o cumprimento das condicionalidades do programa a atual cobertura da Estratégia de Saúde da Família. As autoras reforçam a ideia de que o acesso aos serviços no território é um dos fatores determinantes para o acompanhamento das condicionalidades. Esta percepção é partilhada por Stechi, (2015) que constata, nas entrevistas com os profissionais dos serviços, a dificuldade de os usuários conseguirem vaga nas escolas e agendamentos nas UBS para seus filhos. Nesse sentido, a elaboração do PTS e a articulação dos setores pode ser dispositivo para ampliar e fortalecer o acesso à rede de serviços.

As análises acerca da rede de assistência social, na revisão de literatura, apontam fragilidades. Magalhães et. al. (2011) ao analisarem a implantação do PBF na região de Manguinhos, na cidade do Rio de Janeiro, apontam que a rede de Centro de Referência em Assistência Social - CRAS existente no município era insuficiente para o acompanhamento dos beneficiários do programa. A insuficiência de serviços de assistência social para o cadastramento e acompanhamento dos beneficiários do programa também é apontada como um problema por Ribeiro (2015), ao analisar o programa no município de Guarulhos - SP. E Senna (2013, p. 261) identifica como obstáculos do cumprimento das condicionalidades do programa em Niterói o funcionamento deficitário dos CRAS e a ausência de agente comunitário de saúde nas equipes de saúde da família.

Araújo et al (2018) em estudo recente sobre o acompanhamento do Programa Bolsa Família em todo país, apontam uma relação direta entre o acesso aos serviços de saúde, educação e assistência social e o efetivo acompanhamento do programa. Neste estudo, regiões que possuem uma rede mais estruturada e acessível de serviços sociais apresentaram melhores resultados nos índices de acompanhamento do programa.

Na USF analisada, não apenas o acesso, mas a integração de ações entre a rede social e de saúde foi considerada elemento chave para o acompanhamento de condicionalidades e redução da vulnerabilidade. $\mathrm{O}$ acesso aos serviços de saúde, assistência social e educação no território pesquisado é assegurado através dos equipamentos sociais existentes (UMSAF, CRAS, creches e escolas), que, apesar da falta de alguns profissionais (agentes comunitários 
de saúde na UMSF e agentes sociais e assistentes sociais no CRAS) são suficientes para o atendimento da população e o acompanhamento das condicionalidades do programa.

Neste sentido, fica clara a necessidade da existência de uma rede de serviços de saúde, educação e assistência social estruturada e preparada para o atendimento dos beneficiários do programa. A dificuldade do acesso a serviços sociais de qualidade nos territórios se constitui como um entrave importante para garantia dos direitos sociais e efetividade do PBF. O acesso a serviços de qualidade está relacionado não apenas à estrutura, mas ao modo de organização do processo de trabalho das equipes de educação, saúde e assistência social que acompanham as famílias beneficiárias do programa.

No processo de implantação do PBF em Manguinhos - RJ, Magalhães et al. (2011) salientam que a falta de informação e a não participação dos serviços na fase de planejamento, fez com que a equipe de saúde da família organizasse um dia da semana para o acompanhamento das famílias beneficiárias do programa. Essa organização do processo de trabalho gerou um cuidado fragmentado, burocratizou as ações de acompanhamento e reforçou o estigma dos beneficiários do programa. Por outro lado Senna (2013), em seu estudo sobre a implantação do PBF no município de Niterói - RJ, ressalta que o acompanhamento das condicionalidades do Programa Bolsa Família não alterou em nada o processo de trabalho das equipes de saúde da família e os profissionais entrevistados apontam um acréscimo de serviço para equipes já sobrecarregadas.

Na rede de serviços sociais, Stechi (2013), em análise do trabalho social desenvolvido com as famílias beneficiárias do programa, aponta que o trabalho da equipe do CRAS deve se pautar na análise das vulnerabilidades das famílias e no estabelecimento de estratégia de enfrentamento das mesmas.

No campo da educação, Oliveira e Santos [201-?] apontam que a simples permanência no ambiente escolar não tem, necessariamente, impacto na inclusão social das famílias. Segundo as autoras, é necessária uma reorganização do processo pedagógico visando aprendizagens significativas por parte dos alunos. Esta afirmação é corroborada por Pires (2013), para quem a manutenção dos alunos na escola não é suficiente para o rompimento das situações de pobreza e desigualdade social, sendo necessário que essas crianças desenvolvam um conjunto de habilidades e destrezas que permitam um melhor desempenho de suas atividades. 
Pires (2013) alerta que a escola, caso não obtenha sucesso na ruptura com o processo histórico de formação das desigualdades e trate desiguais de modo igual pode ser, paradoxalmente, um instrumento eficaz de manutenção das desigualdades sociais.

A análise dos processos de trabalho da UMSF deixa clara a importância dos serviços sociais serem organizados segundo as necessidades dos usuários e a existência de mecanismos concretos de identificação, acolhimento e a assistência às famílias com maior vulnerabilidade no território. A unidade pesquisada conta com uma ampla gama de serviços assistenciais e socioeducativos, desenvolvidos pela equipe da unidade em parceria com a equipe do NASF, favorecendo a ruptura do modelo hegemônico de cuidado em saúde, pautado na queixa e com foco na doença, possibilitando um olhar ampliado para os condicionantes e determinantes do processo saúde-doença existentes no território. As reuniões periódicas de equipe para discussão dos casos e a elaboração de projetos terapêuticos singulares possibilitam um olhar para as situações de maior vulnerabilidade e o estabelecimento de estratégias de enfrentamento ou redução das dessas situações. O olhar para as situações concretas de maior vulnerabilidade social favorece a compreensão dos fatores geradores e mantenedores da desigualdade e da exclusão social no território usado, rompendo com o olhar homogeneizante sobre a pobreza e a identificação das rugosidades existentes no território, favorecendo a noção de comunidade e possibilitando a construção de projetos coletivos de enfrentamento da situação atual.

Esse olhar emancipatório do programa Bolsa Família, pautado na lógica da proteção social, é mais facilmente estabelecido se for construído coletivamente pelas equipes que atuam nos territórios, a partir de ações intersetoriais.

A atuação intersetorial a partir dos territórios é fundamental para compreensão ampliada das vulnerabilidades que as famílias beneficiárias do programa estão submetidas e para redução das desigualdades sociais. Ressalte-se que o conceito de vulnerabilidade implica não apenas os aspectos negativos, mas, na mesma medida, os recursos que podem ser mobilizados pelas pessoas e comunidades para fazer frente a situações de risco (AYRES, 2003).

A intersetorialidade aparece como um dos objetivos básicos do PBF, sendo as ações intersetoriais fundamentais para superação da fragmentação das políticas públicas e para otimização dos recursos existentes. Pressupõe deslocamentos de poder, o estabelecimento de compromissos, projetos comuns e o compartilhamento de informações e recursos (SANTOS, 2013; SENNA, 2013; MAGALHÃES et al., 2011) 
Apesar de ficar clara a importância da intersetorialidade para o acompanhamento das condicionalidades do programa, diversos autores ressaltam as dificuldades de sua efetivação no dia a dia das equipes. Uma dessas carências é a fragilidade das ações intersetoriais no acompanhamento das condicionalidades do PBF está associada à baixa articulação entre os setores de saúde, educação e assistência social, à falta de gestão intersetorial e à atuação fragmentada das políticas sociais nos territórios, dificultando o atendimento integral às famílias beneficiadas (SENNA, 2013; STECHI, 2015).

Ao analisar a gestão intersetorial do Programa Bolsa Família no município de Guarulhos - SP Santos (2011) ressalta o fato de que as ações intersetoriais no município se dão de forma pontual para solução de problemas cotidianos enfrentados pelas equipes. Essa afirmação é compartilhada por Ribeiro (2011) em sua dissertação de mestrado sobre a implantação odo Programa Bolsa Família no mesmo município, ressaltando que há uma intencionalidade da gestão municipal para efetivação de ações intersetoriais na gestão e acompanhamento do programa, porém, na prática, essas ações não estão consolidadas, se dando na maioria das vezes a partir de relações pessoais entre profissionais e gestores dos serviços nos territórios.

Sousa, Santana e Valensuela (2017) salientam a importância da construção conjunta entre as equipes de saúde, educação e assistência social de protocolos e fluxos de atendimento e do compartilhamento permanente das ações realizadas, desde o planejamento ao monitoramento conjunto dos resultados. Stechi (2013) enfatiza a importância de que este trabalho se constitua em rede e seja focado no território, de modo articulado.

A comunicação e o acesso igualitário às informações compõem um dos desafios para a intersetorialidade no Programa Bolsa Família. Magalhães et. al. (2011) apontam diversas dificuldades para o acompanhamento das condicionalidades e para atuação intersetorial, como o acesso desigual às informações do programa, falta de articulação entre as equipes que acompanham as famílias, falta de capacitação dos profissionais e a delimitação do território de abrangência.

Carmo e Guizardi (2017) ao discutirem os desafios da intersetorialidade entre as políticas públicas de saúde e assistência social, ressaltam que ambas partem de uma concepção territorial e que as equipes atuam nos mesmos territórios concretos, podendo potencializar mutuamente suas ações. Apontam como desafios a serem superados para efetivação da intersetorialidade: as diferentes concepções sobre o tema, as disputas entre os setores por recursos e poder, as ações intersetoriais construídas informalmente a partir da 
atuação dos gestores e trabalhadores a nível local, a organização burocrática das políticas setoriais e a baixa participação popular. Apesar dos desafios as autoras reafirmam a importância da intersetorialidade para superação da fragmentação das políticas sociais e a ampliação da capacidade de compreensão das necessidades dos usuários e construção de ações que visem a redução das vulnerabilidades que estão submetidos. Salientam que para efetiva ação intersetorial é necessário o diálogo entre as equipes, favorecendo a troca de saberes e a construção de projetos com objetivos comuns.

A análise da intersetorialidade na unidade de saúde da família pesquisada demonstra desafios semelhantes aos apontados na bibliografia estudada. As ações intersetoriais se dão de modo informal, dependendo da iniciativa dos gestores e dos trabalhadores dos serviços sociais existentes no território usado. A falta de instrumentos de planejamento conjunto entre as políticas sociais, a fragmentação dos sistemas de informação e a sobrecarga de trabalho das equipes, dificulta muito as ações intersetoriais. Apesar desses desafios alguns fatores contribuem para intersetorialidade. A realização de projetos terapêuticos intersetoriais, com a participação das diversas equipes, para atuação junto às famílias com alta vulnerabilidade social e de saúde favorecem a aproximação entre as equipes e a atuação conjunta. $\mathrm{O}$ planejamento conjunto entre a unidade de saúde da família, as creches e escolas das ações do Programa Saúde nas Escolas PSE, do Ministério da Educação, favorece o desenvolvimento de ações articuladas de prevenção e promoção da saúde junto às crianças e familiares. A realização de ações articuladas entre a unidade de saúde e o CRAS, como o grupo de cuidadores, favorecem a proximidade entre as equipes e a ampliação do olhar para as situações de maior vulnerabilidade social.

A revisão bibliográfica apresentou experiências positivas de integração. Senna (2103) ressaltou que a criação do Comitê Gestor Intersetorial municipal, operando como uma arena negociação dos diferentes interesses, foi um avanço para implantação e discussão do programa.

Magalhães et. al. (2011), no acompanhamento do PBF em Manguinhos, relatam que foram criadas instâncias de articulação municipal e regional entre as secretarias envolvidas no acompanhamento do PBF. Porém, a efetividade dessas instâncias colegiadas foi reduzida por uma série de fatores, como a falta de uma agenda de trabalho e de informação sobre repartição de recursos entre as diferentes secretarias do poder municipal envolvidos no programa.

No caso em estudo, um projeto recente de articulação dos serviços sociais existentes no território, liderado pelo CRAS e a UMSF, tem potencial para ampliação da atuação em 
rede e o fortalecimento da intersetorialidade. Na primeira reunião foram convidados os representantes dos serviços públicos (CRAS, UMSF, creches, escolas municipais e estaduais), religiosos (pastorais da igreja católica e representantes das igrejas evangélicas) e comunitários (escolinha de futebol e judô), que apresentaram todos serviços realizados com os diversos grupos prioritários (crianças, adolescentes, famílias e idosos) e começaram a pensar em possíveis articulações entre eles. No próximo encontro serão agrupados os serviços desenvolvidos no território por grupo e estabelecidas estratégias de articulação das ações. Em um terceiro momento serão estabelecidos projetos conjuntos para o enfrentamento das situações de maior vulnerabilidade.

Iniciativas como essa tendem a diminuir a fragmentação existente entre as políticas sociais e ampliar a possibilidade de interferência nas situações de maior vulnerabilidade. $\mathrm{O}$ envolvimento das lideranças comunitárias favorece a noção de comunidade e a construção coletiva de projetos que impactem na realidade do território usado.

\section{Considerações finais}

O PBF tem como objetivos o alívio imediato da pobreza por meio da transferência de renda às famílias pobres, a ruptura do ciclo intergeracional da pobreza, a ampliação dos direitos sociais básicos e a disponibilização de ações e programas complementares que qualifiquem a oferta de serviços e apoiem o desenvolvimento das famílias.

As condicionalidades do programa se constituem como um compromisso de mão dupla entre as famílias beneficiadas e o poder público, favorecendo o acesso às políticas de saúde, educação e assistência social, promovendo melhoria da qualidade de vida e ampliação da oferta de serviços nos territórios em conformidade com as necessidades dos usuários.

A revisão bibliográfica e a reflexão crítica propiciada pela prática cotidiana do trabalho em uma equipe de saúde da família evidenciaram que o acompanhamento das condicionalidades do PBF pode favorecer o acesso das famílias com maior vulnerabilidade social aos serviços de saúde, educação e assistência social e a ampliação dos direitos sociais. Porém, para que isso se efetive, é necessário que os gestores e os profissionais que operam as políticas sociais nos territórios compreendam as condicionalidades a partir de um olhar emancipatório e de garantia de direitos, rompendo com a histórica postura fiscalizatória/punitiva das políticas sociais no Brasil, baseadas numa concepção assistencialista e de meritocracia, rompida, no plano jurídico, com a Constituição de 1988. 
Para tanto é fundamental que sejam observados os seguintes aspectos: a) a concepção que os profissionais de saúde, educação e assistência social têm sobre direitos sociais, pobreza, desigualdade social e exclusão social influenciará diretamente a relação que eles estabelecem com os usuários e o caráter do programa; b) a prática dos profissionais que operam o programa deve ser pautada por um olhar ampliado sobre a pobreza e a desigualdades social, desconstruindo a visão homogeneizante para compreender sua singularidade, em especial como estes fenômenos se materializam no território em que as equipes atuam; c) outro ponto norteador das práticas dos profissionais é a compreensão da complementaridade entre desigualdade social, um fenômeno socioeconômico e exclusão social, um fenômeno cultural e social. Essa compreensão permite aos profissionais entenderem que a transferência de renda tem impacto na desigualdade social, mas não interfere diretamente nos fatores geradores da exclusão social.

Para atuar sobre os elementos geradores e mantenedores da exclusão social é necessário compreender como esses fatores se constituem de modo concreto e simbólico no território de atuação das equipes. O olhar preconceituoso verificado por Stechi (2015) nas entrevistas com gestores e profissionais que operam o programa, em que os mesmos pautavam sua prática na crença que os pobres são incapazes por si só de tomar decisões racionais, devendo ser constrangidos através das condicionalidades a adequar seu comportamento ao esperado pela sociedade, é incompatível com o cumprimento de um dos objetivos estruturantes da Política Nacional de Assistência Social, tornar visíveis os invisíveis em nossa sociedade. Esse tipo de representação social dos usuários dificulta a ruptura do olhar homogeneizante da pobreza e impede os profissionais de enxergarem os usuários reais, com suas vulnerabilidades e potencialidades.

A compreensão das condicionalidades na ótica proposta por Ximenes e Agatte (2011) e Silva e Alcântara (2012), que identificaram as vulnerabilidades socioespaciais a que as famílias acompanhadas estão submetidas e a repercussão dessas vulnerabilidades sobre o acesso aos serviços sociais, possibilita a intervenção mais efetiva, territorial, das equipes para redução das vulnerabilidades. A atuação com este viés potencializa os recursos dos indivíduos e famílias e amplia o acesso aos serviços de saúde, educação e assistência social, favorecendo a redução da desigualdade não monetária (ARRETCHE, 2017).

O acesso, a qualidade e o modo de organização do processo de trabalho dos serviços sociais é identificado tanto na pesquisa bibliográfica como empírica como um fator determinante para o acompanhamento efetivo das condicionalidades. 
A falta de serviços sociais no território, o déficit de pessoal e/ou processos de trabalho burocratizados impedem as equipes de se aproximarem dos usuários e suas famílias, dificultando a realização de ações que busquem a redução das vulnerabilidades e ampliação das potencialidades das famílias acompanhadas.

Por outro lado, a análise do processo de trabalho da equipe de saúde da família, permite verificar a importância do acompanhamento próximo das famílias com maior vulnerabilidade. A construção coletiva de projetos terapêuticos para as famílias de maior vulnerabilidade permite a compreensão dos fatores concretos e simbólicos geradores da exclusão social e o estabelecimento de ações para intervenção nos mesmos. Além disso, possibilita a ampliação do olhar sobre o processo saúde-doença e a ruptura com o modelo biomédico, centrado na doença, permitindo a efetivação de uma clínica ampliada, pautado em uma compreensão biopsicossocial de saúde e doença.

A intersetorialidade aparece como umas das potencialidades do programa e simultaneamente como um dos maiores desafios, exigindo dos gestores e das equipes uma postura cooperativa e de planejamento conjunto de ações, visando à articulação das ações junto às famílias acompanhadas pelo programa. É esta intersetorialidade que permite um olhar ampliado sobre os territórios usados, os lugares, como entendido por Milton Santos (2005, 2006), favorecendo a compreensão da comunidade em que os usuários e famílias estão inseridos.

A comunidade se constitui como um elemento fundamental para atuação das equipes de saúde, educação e assistência social nos territórios, por permitir aos usuários o desenvolvimento de relações empáticas com os outros a sua volta, através dos espaços intersubjetivos, que favorecem comunicação, diálogo, identidades sociais, memória social e vida pública.

A atuação das equipes junto às comunidades favorece o desenvolvimento de soluções para os problemas sociais, por fortalecer a participação dos usuários e dos profissionais na esfera pública, lugar em que são produzidos os saberes sobre si próprio, as representações sociais.

A compreensão sobre as comunidades em que os usuários estão inseridos é fundamental para ressignificar os elementos simbólicos que mantém a exclusão social e para compreensão das rugosidades existentes no território, que poderão trazer consigo possibilidades de intervenção das equipes nas vulnerabilidades e nos fatores geradores da exclusão social. 
O Programa Bolsa Família se constitui, efetivamente, como uma estratégia para o enfrentamento da pobreza, da desigualdade social e da exclusão social. Facilitando e ampliando o acesso aos serviços de saúde, educação e assistência social nos territórios e favorecendo ações intersetoriais junto às famílias beneficiárias, se implementado na perspectiva emancipatória em que foi concebido, não apenas poderá modificar as vulnerabilidades socioterritoriais que caracterizam tais famílias como apoiará a construção de redes de apoio intersetoriais e, consequentemente, o fortalecimento da comunidade para busca de soluções de seus problemas.

\title{
BOLSA FAMÍLIA: POTENTIALITIES AND CHALLENGES IN THE TERRITORY AS A PUBLIC POLICY INDUCER
}

\begin{abstract}
This paper analyses both the potential and limits of the Bolsa Familia program for governing the social policies in the territories, favoring access to basic social rights and lessening social exclusion of the families assisted. The concepts of place and used territory, according to Milton Santos, and the notions of social representation and community guided the literature review, having the territorial perspective of social policies as the theoretical background. The literature review, combined with reflections on the daily practice in a Family Care primary unit located in a medium size municipality in the State of São Paulo, showed that follow-up of the Bolsa Familia conditionalities may favor access to health, education and social services by the more socially vulnerable families, and span social rights, thus mitigating social exclusion. Nevertheless, if such is to be achieved, managers and health workers that operate the social policies in the territories ought to understand the conditionalities under an emancipatory and assurance of rights perspective, disrupting the inspection/punitive attitude grounded on conceptions of charitable support and meritocracy. The provision of access to services of quality in the territories, organized in order to assure the citizens' basic social rights, is also required. Intersectoral actions allow for a more comprehensive view of the used territories, contributing for the professionals to better understand the community in which the users and their families live and perform.
\end{abstract}

Key words: Territory, social policies, Bolsa Família social program.

\section{Referências}

AMARAL, E. F. de L.; MONTEIRO, V. do P. Avaliação de Impacto das Condicionalidades de Educação do Programa Bolsa Família (2005 e 2009). Revista de Ciências Sociais, Rio de Janeiro, v. 56, n. 3, 2013.

ARAÚJO, F. R. Distribuição espacial do desempenho do Programa Bolsa Família: um estudo à luz do IGD-M. Revista de Ciências Sociais, Rio de Janeiro, v. 61, n. 3, 2018, p. 773 - 806.

ARRETCHE, Marta. Democracia e redução da desigualdade econômica no brasil: a inclusão dos outsiders. Revista Brasileira de Ciências Sociais. São Paulo, v. 33, n. 96, 2018. 
AYRES, J.R.C.M et al. O Conceito de Vulnerabilidade e as práticas de saúde: novos desafios e perspectivas. In: Czeresnia, D; Machado Freitas, C (Org.). Promoção da Saúde: conceitos, reflexões, tendências. Rio de Janeiro: Fiocruz, 2003. p. 116-138

BRASIL. Constituição, 1988. Disponível em:

< http://www.planalto.gov.br/ccivil_03/constituicao/constituicao.htm>. Acesso em: 25 jan. 2017.

BRASIL. Lei no 10.836, de 9 de janeiro de 2004. Cria o Programa Bolsa Família e dá outras providências. Disponível em: http://www.planalto.gov.br/ccivil_03/_ato20042006/2004/lei/110.836.htm. Acesso em: 19 jun. 2017.

BRASIL. Ministério de Desenvolvimento Social e Combate à Fome. Norma Operacional Básica - NOB/SUAS. Brasília, 2005a.

Brasil. Ministério da Saúde. Secretaria de Atenção à Saúde. Núcleo Técnico da Política Nacional de Humanização. Clínica ampliada, equipe de referência e projeto terapêutico singular / Ministério da Saúde, Secretaria de Atenção à Saúde, Núcleo Técnico da Política Nacional de Humanização - 2. ed. - Brasília: Ministério da Saúde, 2007. 60 p. (Série B. Textos Básicos de Saúde)

CARIELLO, Rafael. O liberal contra a miséria. Revista Piauí, São Paulo, n. 80, mai. 2013.

CARMO, M. E.; GUIZARDI, F. L. Desafios da intersetorialidade nas políticas públicas de saúde e assistência social: uma revisão do estado da arte. Physis Revista de Saúde Coletiva, Rio de Janeiro, v. 27, n. 4, p. 1265-1286, 2017.

CURRALERO, C. R. B.; AFONSO, A. F. O índice de gestão descentralizada (igd) e o sistema de condicionalidades (sicon) como ferramentas de gestão intersetorial do programa bolsa FAMíLIA. In: IV Congresso CONSAD de Gestão Pública, Brasília, DF, 2011.

FLEURY, Sonia. Espaço, território e cidadania: a cidade dos cidadãos. VIII Congresso Luso-Agro-Brasileiro de Ciências Sociais, 2004, Coimbra, Portugal. Cento de Estudos Sociais, Faculdade de Economia, Universidade de Coimbra, 2004. Disponível em: http://app.ebape.fgv.br/comum/arq/ACFD527.pdf. Acesso em: 19 jun. 2018.

Desigualdades injustas: o contradireito à saúde. Cebes, Rio de Janeiro, 2012. Disponível em : http://cebes.org.br/2012/05/artigo-de-sonia-fleury/. Acesso em: 27 nov. 2018

FLEURY, S.; OUVERNEY, A. M. Política de saúde: uma política social. In. GIOVANELLA, L. et. al. Políticas e sistema de saúde no Brasil. Rio de Janeiro, Editora Fiocruz, 2 ed., rev., amp; 2014. p.25-57, tab, graf. Disponível em: http://www.escoladesaude.pr.gov.br/arquivos/File/TEXTO_1_POLITICA_DE_SAUDE_POL ITICA_SOCIAL.pdf. Acesso em: 27 nov. 2018

IPEA - INSTITUTO DE PESQUISA ECONÔMICA APLICADA. Determinantes imediatos da queda da desigualdade de renda brasileira. Texto para discussão. Rio de Janeiro, Ipea, jan. 2007. 
IPEA - INSTITUTO DE PESQUISA ECONÔMICA APLICADA. A redução da desigualdade e seus desafios. Brasília, Ipea, jan. 2015.

JOVCHELOVITCH, Sandra. Vivendo a vida com os outros: intersubjetividade, espaço público e Representações Sociais. In. GUARESCHI, Pedrinho Arcides;

JOVCHELOVITCH, Sandra (Org.). Textos em representações sociais. Petrópolis: ed. Vozes, 1995.

Psicologia social, saber, comunidade e cultura. Psicologia \& Sociedade, v. 16, n. 2, p. 20-31, maio/ago.2004. Disponível em: http://www.scielo.br/pdf/psoc/v16n2/a04v16n2. Acesso em: 27 nov. 2018

KOGA, D.; NAKANO, K. Perspectivas territoriais e regionais para as políticas públicas brasileiras. In: A Abong nas Conferências 2005 Criança e Adolescente - Assistência Social, Brasília, 2005.

KOGA, Dirce. Aproximações sobre o conceito de território e sua relação com a universalidade das políticas sociais. Serviço Social em Revista, Londrina, v. 16, n.1, p. 3042, jul./dez. 2013.

MAGALHÃES et. al. Intersetorialidade, Convergência e Sustentabilidade: Desafios do Programa Bolsa Família em Manguinhos, RJ. Ciência e Saúde Coletiva, n. 16, v. 11, p. 4443-4453, 2011.

OLIVEIRA, S.S.B.; SANTOS, S. D. F. Política pública de transferência de renda e educação: um estudo sobre o programa bolsa família na esfera escolar. Acessado através do link: http://www.estudosdotrabalho.org/texto/gt2/politica_publica.pdf acesso em: $17 / 06 / 2017$

PIRES, André. Afinal, para que servem as condicionalidades em educação do Programa Bolsa Família? Avaliação em Políticas Públicas em Educação, Rio de Janeiro, v. 21, n. 80, p. 513 532, jul./set. 2013.

PMJ. Relatório de arrolamento consolidado de agosto de 2019 da Unidade Municipal de Saúde da Família do Parque Meia Lua. Jacareí, 2019.

RIBEIRO, Maria de Jesus Assis. Gestão municipal do Programa Bolsa Família e possibilidades locais de intersetorialidade: o caso da cidade de Guarulhos do Estado de São Paulo. 2015. 179 f. Dissertação (Mestrado em serviço social), Pontifícia Universidade Católica de São Paulo, PUCSP, São Paulo, 2015.

SANTOS, Boaventura de Souza. A construção multicultural da igualdade e da diferença. Centro de Estudos Sociais, Coimbra, oficina do CES, n. 135, jan. 1999. Disponível em: http://www.do.ufgd.edu.br/mariojunior/arquivos/construcao_multicultural_igualdade_diferen ca.pdf. Acesso em: 28 nov. 2018

SANTOS, Milton. O retorno do território. OSAL: Observatório Social da América Latina. Buenos Aires, ano 6, n. 16, jun. 2005. Disponível em: <http://bibliotecavirtual.clacso.org.ar/ar/libros/osal/osal16/D16Santos.pdf >. Acesso em: 25 jan. 2017. 
SANTOS, Milton. A natureza do Espaço: técnica e tempo, razão e emoção. 4 ed. 2. reimpr. São Paulo, ed. Universidade de São Paulo, 2006.

SANTOS, R. L. A. dos; LICIO, E. C. Resultados e desafios do acompanhamento das condicionalidades do programa bolsa família. In: IV Congresso CONSAD de Gestão Pública, Brasília, DF, 2011.

SANTOS, Natalia Navarro dos. Os Desafios da Gestão Intersetorial do Programa Bolsa Família: o Caso do Município de Guarulhos. In: XXXV Encontro da ANPAD, Rio de Janeiro, 2011.

SENNA, Mônica de Castro Maia. Ações intersetoriais envolvendo assistência social e saúde: o programa bolsa família em questão. O Social em Questão, Rio de Janeiro, ano 17, n. 30, p. $245-272,2013$.

SOUSA, A. L.; SANTANA, P. L.; VALENSUELA, K. P. Programa bolsa família e intersetorialidade. In: IV Jornada de estudos em Serviço Social, Universidade Estadual do Paraná, UNESPAR Campus Paranavaí, 2017.

STECHI, Tatiana de Oliveira. O Programa Bolsa Família a partir do território: o trabalho social com as famílias beneficiárias. Serviço Social em Revista, LONDRINA, v. 16, n.1, p. 167-192, jul./dez. 2013

O programa bolsa família e suas condicionalidades: entre o direito e o dever. 2015. 163 f. Dissertação (Mestrado em Serviço Social e Política Social), Universidade Estadual de Londrina, UEL, Londrina, 2015.

SILVA, W. W. da; ALCÂNTARA, S. A. Desafios na gestão do programa bolsa família na saúde. Caderno Gestão Pública, São Paulo, ano.1, n.1, jul./dez. 2012

XIMENES, D. A.; AGATTE, J. P. A gestão das condicionalidades do Programa Bolsa Família: uma experiência intersetorial e federativa. Inclusão Social, Brasília, DF, v. 5 n. 1, p.11-19, jul./dez. 2011.

Data de recebimento: 29/07/2019

Data de aceite: $13 / 11 / 2019$

\section{Sobre os autores:}

Eduardo Guadagnin é Doutorando em Planejamento Urbano e Regional pela Universidade do Vale do Paraíba, Mestre em Saúde Pública pela Faculdade de Saúde Pública da USP (2013). Graduado em Licenciatura e Psicologia pela Universidade de Taubaté (1993). Especialista em Saúde Pública pela UNICAMP (2000), especialista em Gestão Pública em Saúde pela Faculdade de Medicina da Santa Casa de São Paulo (2010) e especialista em Formação integrada multiprofissional em Educação Permanente em Saúde pela UFRGS (2015). Atua como psicólogo em Unidade de Saúde da Família no município de Jacareí e como professor na Universidade do Vale do Paraíba, nas faculdades de Biomedicina, Odontologia, 
Enfermagem, Nutrição, Estética, Fisioterapia e Psicologia, nas disciplinas de Saúde Coletiva, Cidadania e Responsabilidade Social, Psicologia Aplicada à Saúde, Práticas Integrativas e Psicologia da Educação. Tem experiência nas áreas de Psicologia, Saúde Coletiva, Gestão Pública em Saúde e em Consórcio Público em Saúde. Possui interesse nos seguintes temas: saúde coletiva, território e processo saúde doença, educação permanente, atenção básica, psicologia, trabalho em equipe e controle social. Endereço Eletrônico: eduguadsjc@gmail.com

Pedro Ribeiro Moreira Neto é Arquiteto e urbanista pela FAU "Elmano Ferreira Veloso" - São José dos Campos (1970-1974) com especialização em Urbanismo - Centre de Recherche dUrbanisme-CRU (Paris 1978); mestrado em "Analyse Régionale et Aménagement de 1?Espace - Institut dEtudes du Developpement Economique et Social - Université Paris I" (1980), doutorado em "Géographie Humaine et Organisation de lEspace - Institut de Geógraphie Université Paris I - Panthéon-Sorbonne" (1982) e História Social - Faculdade de Filosofia Letras e Ciências Humanas FFLCH - Universidade de São Paulo-USP (2002). Atua também em Fotografia, Vídeo e Artes Plásticas, com interesse em temas sócio-culturais. É produtor cultural e docente do Programa de Pós-graduação em Planejamento Urbano e Regional da Universidade do Vale do Paraíba - UNIVAP, consultor do Banco Interamericano de Desenvolvimento BID / Mecanismo Independente de Consulta e Investigação MICI. Foi membro do Conselho Consultivo da Região Metropolitana do Vale do Paraíba, Serra da Mantiqueira e Litoral Norte SP, também secretário de Meio-Ambiente e de Planejamento em Jacareí-SP 2001/2004 e de Planejamento Urbano em São José dos Campos-SP 2015/2016. Endereço Eletrônico: pedroribeiro@univap.br

Paula Vilhena Carnevale Vianna possui graduação em Medicina pela Universidade Federal de São Paulo (1991), mestrado em Infectologia pela Universidade Federal de São Paulo (1997) e doutorado em Medicina (Medicina Preventiva) pela Universidade de São Paulo (2004). Experiência no campo do cuidado, gestão e educação em saúde. Há dez anos atua como docente no campo da Saúde Coletiva e Ciências Humanas e Sociais em Saúde. Interesse especial na área de história das políticas de saúde e sua relação com o processo de urbanização, bem como pela interface saúde/espaço, área de atuação nas atividades de pesquisa, ensino e extensão. Endereço Eletrônico: paula.cvianna@ anhembi.br 